\title{
Developing a Collaboration with the Houston Independent School District: Testing the Generalizability of a Partnership Model
}

\author{
Jeanne Poduska • Mary Jane Gomez • \\ Zeph Capo • Venita Holmes
}

Published online: 20 December 2011

(C) The Author(s) 2011. This article is published with open access at Springerlink.com

\begin{abstract}
Moving evidence-based practices into realworld settings is a high priority for education and public health. This paper describes the development of a partnership among the Houston Independent School District, the American Institutes of Research, and the Houston Federation of Teachers to support research on and program sustainability for the Good Behavior Game, a team-based classroom behavior management strategy that has shown positive impact in randomized field trials. The conceptual framework guiding partnership development is presented, followed by an application of the framework in Houston. Lessons learned and implications for the next stage of research and practice are then discussed.
\end{abstract}

Keywords Researcher-practitioner partnerships . Community-based participatory research $\cdot$ Mental health

Ideas reflected in this paper have been presented at the IES Research Conference, June 2010, in Washington, DC, and the Advancing School Mental Health Conference, October 2010, in Albuquerque, NM.

\section{J. Poduska $(\square)$}

American Institutes for Research, 300 East Lombard St., Suite 1020, Baltimore, MD 21202, USA

e-mail: jpoduska@air.org

\section{J. Gomez}

Early Childhood Department, Houston Independent School District, Houston, TX, USA

\section{Z. Capo}

Houston Federation of Teachers, Houston, TX, USA

\section{Holmes}

Department of Research and Accountability, Houston Independent School District, Houston, TX, USA research - School-based programs - Aggressive $\cdot$ Disruptive behavior · Prevention - Evidence-based prevention . Good behavior game

\section{Introduction}

Schools are a normative setting for children and an important delivery system for mental health and prevention programs. Yet, even though a number of school-based prevention programs have shown a positive impact in epidemiologically-based randomized field trials, the outcomes seen in highly controlled studies are often not replicated when programs are moved into general practice.

Until fairly recently, the usual strategy for program development in education and prevention has been to develop interventions, test them through rigorous studies employing random assignment, and then offer them to community institutions. The implicit expectation of this strategy is that institutions will adopt the evidence-based programs and implement them with a high degree of fidelity to the intended practices. While unrealistic, this expectation is not unique to any particular field. The field would benefit from models of researcher-community institution partnering to ensure that programs, as developed, are applicable and relevant to institutions and that institutions are ready to adopt and scale up programs as they are proved effective. Such partnerships can support programmatic success as programs are proved efficacious and can provide opportunities for ongoing research.

This paper describes the development of a partnership among the American Institutes for Research (AIR), the Houston Federation of Teachers (HFT), and the Houston Independent School District (HISD) to support research on and programmatic sustainability of the Good Behavior Game, 
a classroom-based behavior management strategy. The Good Behavior Game (GBG) is one of the few preventive interventions showing both short-term and long-term impacts through epidemiologically-based randomized field trials. The conceptual framework guiding partnership development is described, followed by an application of the framework in Houston. Lessons learned and implications for the next stage of research and practice are then discussed.

\section{The Inception of the Partnership and the Problem to be Addressed}

At the start of the AIR-HISD partnership, Poduska, an author on the paper and a researcher at AIR, had worked on three randomized field trials of GBG (Dolan et al. 1993; Ialongo et al. 1999; Poduska et al. 2009) conducted in partnership with the Baltimore (MD) City Public Schools. In January 2008, she was invited by the American Federation of Teachers (AFT), the second largest teachers' union in the United States, to speak about prevention, the alignment of education and public health, and GBG to state and local member leaders whose districts were concerned about safety in their schools.

A large body of research shows that children who exhibit aggressive, disruptive behavior upon entering first grade and do not successfully master behavioral expectations are at risk of a range of poor educational and public health outcomes throughout their school years and into young adulthood (Dishion et al. 1996; Ensminger and Slusarcick 1992; Kellam et al. 1998; Kellam et al. 1994; Patterson et al. 1992). Teachers, especially elementary school teachers (Walter et al. 2006) and beginning teachers, rate classroom behavior management as a pressing need (Evertson and Weinstein 2006). Yet, teachers have limited tested tools to help disruptive students modify their behavior. Further, classroom management is not a priority of preservice teacher training, and the National Council for Accreditation of Teacher Education (NCATE) does not require proof of proficiency in this area for teachers to be certified (NCATE 2002).

GBG is aimed at reducing aggressive, disruptive behavior, a confirmed early antecedent risk factor for drug use and abuse (Barrish et al. 1969). GBG is a team-based, group-contingent classroom behavior management strategy that helps children master the role of student and be successful at the key demands of the classroom, including sitting still, paying attention, and completing school work. Through GBG, children work together to create a positive learning environment by monitoring their own behavior as well as that of their classmates. As a strategy not a curriculum, GBG does not compete with instructional time.
In the first randomized field trial, GBG was delivered to children in first and second grades. Short-term results included reductions in off-task behavior (Brown 1993) and aggressive/ disruptive behavior (Dolan et al. 1993). Mid-term impacts included reductions in aggressive/disruptive behavior through middle school (Kellam et al. 1994, 1998). Males who had been in GBG classrooms initiated use of tobacco at a later age than their counterparts who did not receive GBG (Kellam and Anthony 1998). At young adulthood, ages 19-21, there was a reduction in the rates of antisocial personality disorder, drug and alcohol abuse and dependence, and tobacco use (Kellam et al. 2008); the use of school-based services for problems with emotions, behaviors, and drug and alcohol use (Poduska et al. 2008); violence (Petras et al. 2008); and suicidal ideation (Wilcox et al. 2008).

In the second randomized field trial, GBG, delivered in first grade, was combined with curricula enhancements and integrated into one Classroom-Centered (CC) intervention. The short-term results for the $\mathrm{CC}$ intervention included reductions in aggressive/disruptive behavior and increases in achievement (Ialongo et al. 1999). Mid-term impacts included fewer conduct problems and reductions in the likelihood of conduct disorder diagnoses, suspensions from schools, and need for or receipt of mental health services at sixth-grade follow-up (Ialongo et al. 2001). By age 13, students who had been in CC classrooms were less likely to have started smoking (Storr et al. 2002) or used cocaine, crack, or heroin (Furr-Holden et al. 2004) compared to their counterparts. At young adulthood, age 19, there was an increase in the rates of high school graduation or receipt of a GED, college attendance, and academic achievement and a reduction in the use of special education services (Bradshaw et al. 2009). Overall, the impact of GBG has been greatest for males who entered first grade exhibiting aggressive/disruptive behavior.

As a result of the AFT meeting, the Houston Federation of Teachers (HFT) expressed interest in bringing GBG to HISD. HFT was interested in establishing a focus on prevention within the district. A review of HISD's programs and policies on behavior and safety revealed that they were aimed mostly at the higher grades. The fact that GBG is a universal preventive intervention that helps teachers socialize children to the role of student through strengthening the classroom environment-the normative setting for teachers and students-is in keeping with HFT's mission to support teachers and students. Further, HFT is dedicated to providing and advocating programs that have a strong research base. Shortly after the AFT meeting, HFT partnered with AIR on a planning grant, funded in fall 2008 by the National Institute on Drug Abuse (NIDA), as a way to begin a conversation about GBG in the Houston area. The planning grant focused on developing community-researcher partnerships; understanding the 
community-level factors that impede or enhance program implementation; and developing a research and practice agenda with the district.

\section{Approach to Collaboration}

An aim of the planning grant was to explore whether the processes of community and institution base-building that had guided the design and conduct of the locally based Baltimore randomized field trials were applicable to a nonlocal researcher-school district partnership. The approach to collaboration is guided by a sociological perspective of organizations, strengthened by a perspective of community and institution base-building and partnership in which the researcher, driven by mutual self-interest, learns about the vision and mission of the community and develops programs within the community's cultural, social, and political context. This perspective has been informed by longstanding principles and theory from public health (Kellam and Branch 1971; Kellam 2000) and community participatory research. The next section presents the six steps in the conceptual framework and describes how lessons from the field have informed AIR's approach to base-building and partnership.

\section{Step 1-Analyze the Social/Political Context}

The analysis of the social/political context provides information about power, authority, and influence in a district and the broader community relative to the topic at hand. Several questions guide the analysis: Who might be proponents on the topic of interest? Who might be detractors? Who has the authority to lead initiatives in these areas? Who has the power to block or stop initiatives? What constituency or agency does this person represent? It is important to understand that power and influence reside at several levels and to consider institutions and groups across multiple levels (school, district, broader community, state, and federal levels).

The analysis has a two-fold purpose- to identify a list of the key informants with whom to meet within the district and the broader community and to identify candidates to provide ad hoc oversight (see Step 5). Key informants are constituent leaders who communicate constituents' priorities, values, and concerns. They have formal authority of office through appointment (e.g., agency heads) or through election (e.g., mayor, union president), or they have informal authority (e.g., a parent leader within a school). They provide information about formal and informal social structures and relationships, as well as a historical perspective on past challenges and successes with similar initiatives. Key informants provide endorsement of the research team to their constituencies in the broader community as the team works through issues of trust.

Step 2-Learn About the Problems, Priorities, and Vision of Community Leaders

Many researchers are trained to conduct research such that the researcher defines a research project, obtains funding for the project, and then "recruits" schools and communities to participate. In contrast to this traditional method, the researcher spends time with community leaders, listening and talking about the problems the community is facing, their priorities of focus, and the vision of where they want to be at a defined future point, such as in $2-5$ years. These conversations are initiated by the researcher saying "I welcome hearing your thoughts on the mission and vision of your organization, agency, group relative to the broad topic of interest" and asking such questions as "What would success look like to you regarding the broad topic of interest?" and "What challenges are you facing toward realizing that vision?"

Step 3-Identify Mutual Self-Interest with and Across the Leadership

Through these conversations, the researcher and the community leaders identify areas of mutual self-interest. It is possible that the areas agreed on for partnering are different than either the researcher or community leaders expected when first exploring a partnership. The researcher and the community leaders may also determine that it is not the right time to work together, leaving open the opportunity for partnering in the future.

\section{Step 4-Fit One's Vision into the Vision} of the Community Leaders

The researcher's vision and research agenda are now aligned with the vision of the community, and the researcher can begin the work of defining the research questions, developing programs, and securing funding with and on behalf of the community.

\section{Step 5-Request Ad Hoc Oversight from District} and Community Leaders

Ad hoc ("for this") oversight ensures that the overall research and practice agenda remains aligned with the community's and that the research design, protocols, measures, and programs reflect the community's needs and are acceptable to community members. 
Step 6-Work Through Issues of Trust

By its very nature, engaging in research or bringing a new program to an organization brings changes to people's daily lives. For example, people may be asked to participate in research activities such as data collection or to participate in training and then use new practices and strategies. Study designs may call for random assignment. Organizations may have to consider reallocating resources. In any change process, it is natural that individuals consider whether the change will be beneficial or harmful to them and to judge where they stand on the issue of trust. There are several types of trust: contractual-do individuals do what they say they will do; confidence-do individuals have the skills and expertise to do what they say they will do; intentional-do individuals have the best interest of others at heart. Developing relationships and maintaining trust are not an event but a process at both the individual and the organization level.

Lessons from the Field Informing the Approach to Collaboration

Lessons from the field also informed AIR's approach to collaboration. The Baltimore trials showed that operating under the aegis and authority of the district and community provides adequate support for research conducted within its confines such as testing the effectiveness of interventions. Moving research into practice with high-quality implementation introduces additional challenges. First, it can be difficult for districts to maintain a clear vision and mission. Superintendents have an impact on program implementation and sustainability through their influence on mission articulation, staffing decisions, and programmatic choice, yet the average tenure of a superintendent in an urban district was 3.1 years in 2006 (Council of the Great City Schools 2009). A hallmark of leadership transition is programmatic and organizational change. Second, sustaining and expanding the reach of interventions are often seen as prohibitively expensive. Districts may have multiple initiatives operating at the same time, led by different departments with little communication across departments, which can create competition for scarce resources. This situation may be compounded by the fact that money from federal grants, foundations, or other partners is often earmarked for specific activities and timeframes. Third, districts rarely develop organizational and governance structures to support programmatic sustainability and scaling-up.

Given these lessons, AIR brought to the collaboration the hypothesis that addressing the challenges of moving evidence-based programs into schools with high-quality implementation over time requires a broad base of community support (Orr 2007; Shirley 1997; Stone 2001). To support the development of a dual research and practice agenda, AIR advocated base-building at two levels-the school district and the broader Houston community.

\section{An Application of the Approach}

The six-step framework is used to describe the first 2 years of the partnership.

Step 1-Analyze the Social/Political Context

In February 2009, AIR and HFT began to analyze the social/political context of the greater Houston area relative to supporting the high-quality implementation of evidencebased programs in the school system, specifically GBG. The analysis was guided by the following questions: Who in the school system and broader community is concerned with issues of classroom behavior management, teacher effectiveness, drug use, delinquency and violence, and school dropout? Who has the authority to lead initiatives in these areas? Who has the power to block or stop initiatives? What constituency or agency does this person represent?

Figure 1 displays the multilevel ecological framework used to map the social/political context in Houston. Power and influence reside at several levels. A range of institutions is represented, including service agencies, government agencies, and universities, as well as groups such as unions and professional organizations. Within HISD, influential and powerful leaders include the superintendent, the school board, unions of teachers and administrators, and central office staff. At the local community level, important groups are the public health system represented through the health department, including mental health and substance abuse; the welfare system, including foster care; the juvenile and adult justice systems; parent groups; local foundations; business interests; the media; and the mayor's office. At the state level, the state department of education, the governor's office, and the General Assembly are critical. At the national level are the national teachers' unions and federal agencies.

Step 2-Learn About the Problems, Priorities, and Vision of Community Leaders

Base-building with the school district began in February 2009, when HFT organized a meeting with AIR and the Chief Academic Officer of the school district. Several hours were spent discussing the vision and mission of the district and how GBG might support the district's priorities, goals, and core values (HISD 2010). The Chief Academic Officer shared HFT's vision of providing 
Fig. 1 Mapping the social/ political context. This figure illustrates the various levels of the social/political context and examples of key constituencies and agencies at each level

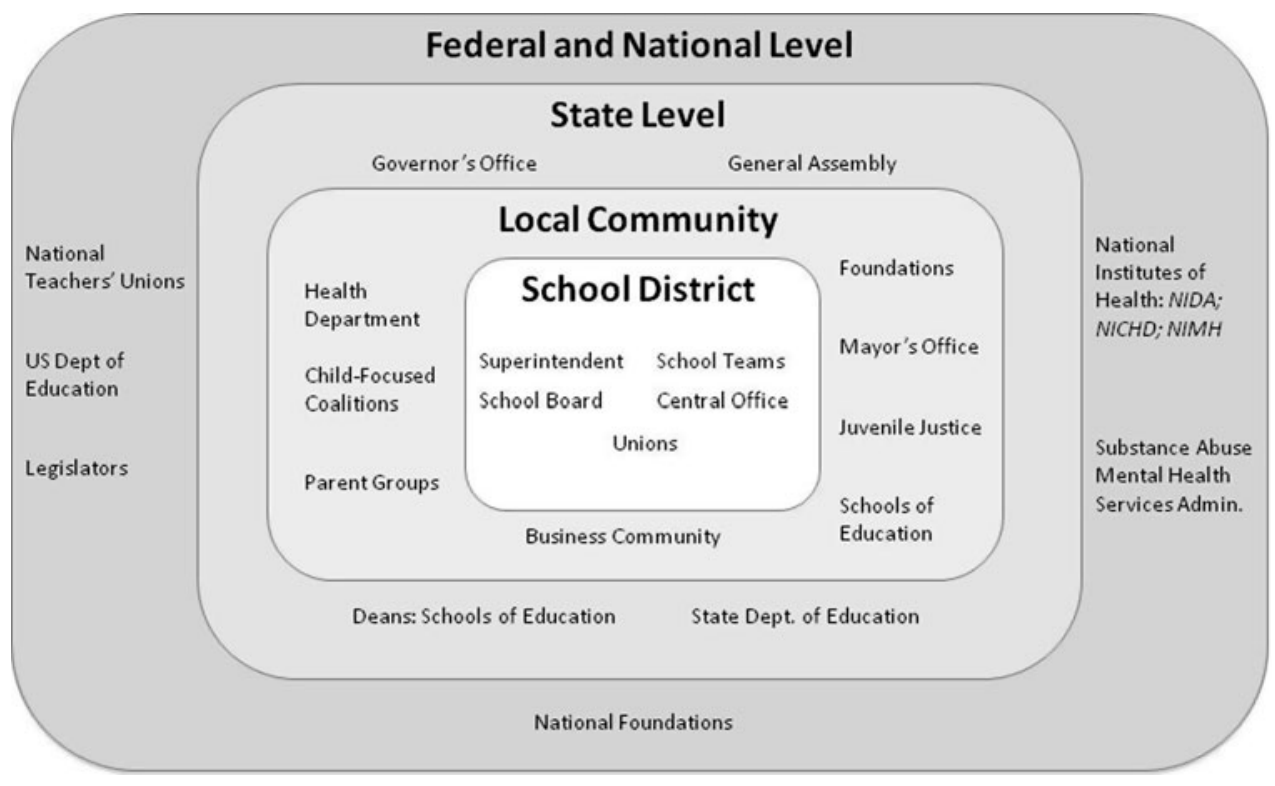

professional development to teachers as a means for effecting change at the student level in light of district findings that classroom teachers routinely indicated classroom management and discipline as one of their greatest challenges and a professional development need.

Base-building activities were also taking place within the broader Houston community. Zeph Capo from HFT (an author on the paper) and other community members undertook the role of preceptor to AIR, a role they have maintained over the past 2 years. Preceptors guide, accompany, and introduce researchers to the community and "connect the team with local agencies, community-based organizations, and special interest groups" (Eng et al. 2005, p. 82). Introduced by these local preceptors, AIR began to meet with key leaders in the greater Houston area. The goals were to understand how GBG fit into the vision and current activities in Houston; learn about successes and challenges regarding program sustainability in general and GBG specifically; and determine other potential key informants-both supporters and detractors. The interviews provided information about the position of individuals on GBG, their interest in the issue, the group or constituency they represent, and their level of power/ influence.

\section{Step 3-Identify Mutual Self-Interest}

The end result of the February meeting with district leadership was a commitment by HISD, HFT, and AIR to develop a research grant. Both HFT and HISD saw a randomized field trial as a way to pilot GBG and begin planning for sustainability and broader implementation. In June 2009, an opportunity arose for HISD to partner with AIR on a randomized field trial funded by the Institute of
Education Sciences (GBG PD study) focused on understanding the level of professional development that teachers need in order to learn, implement, and sustain GBG over time.

\section{Step 4-Develop a Common Vision}

Developing a common vision was complicated by changes in the leadership and organization in HISD. HFT and AIR had met with the Chief Academic Officer in February 2009, but by the end of June 2009, she had resigned and the superintendent announced that he would retire August 31, 2009. A new superintendent would not be confirmed and assume responsibility for several months. It was critical to reestablish a base of support and assess who held power and influence during this time of transition since no district staff were empowered to commit HISD's participation in a new venture.

HFT organized meetings for AIR researchers to present GBG and the GBG PD study to the district. The meetings were attended by school board members; central office staff from various departments; regional assistant superintendents and executive principals, the line of authority and supervision for schools; and school principals. HFT also highlighted GBG at several events. For example, GBG and the GBG PD study were featured at the Houston stop of the 2009 American Federation of Teachers Back-to-School Tour. HFT building stewards received information during the annual fall seminar.

These activities allowed school board members, who had the power to commit HISD to a new initiative in the absence of a superintendent, to reassess the fit of GBG and the GBG PD study with the needs and vision of the district and to gauge the interest of those who would be most 
directly impacted, namely, principals and teachers. Indeed, several school board members wrote letters of commitment on behalf of the district. Mary Jane Gomez, the manager of the Office of Early Childhood (an author on the paper) was named the HISD study liaison under the aegis of the Assistant Superintendent, Elementary Curriculum, Instruction, and Assessment.

\section{Step 5-Request Ad Hoc Oversight from District} and Community Leaders

The goals of the GBG PD study for the 2009-2010 school year were to develop a presence and a base of support within HISD for the GBG PD study and GBG implementation more broadly; select schools for participation in the study; and engage with school communities, including principals, teachers, and parents. AIR, in consultation with the HISD study liaison and HFT, developed a calendar of pre-implementation activities. School selection was scheduled to occur between December 2009 and February 2010. Between February and May 2010, the focus would turn to engaging with principals, teachers, school staff, parents, and the broader school communities of the schools participating in the GBG PD study.

In keeping with the Baltimore trials, AIR proposed establishing two district ad hoc committees, each to be chaired by the HISD study liaison (Poduska et al. 2009). The first committee would be a Core Team comprising individuals in key positions of authority in HISD, along with senior members of AIR's team and HFT. District membership would include representation of HISD departments that would be impacted by the GBG PD study and GBG implementation (Curriculum and Instruction, Student Support Services, Multilingual Education, Research and Accountability, and Professional Development) and representation of the regional assistant superintendents and executive principals who supported and supervised principals and school teams. The key responsibilities of a Core Team would be to monitor the overall implementation of the GBG PD study, including school selection; to ensure that the study remained aligned with the direction and activities of the district; and to work toward the institutionalization of GBG. The second committee would be a Schools Committee comprising the principals of schools participating in the GBG PD study. Their purview would be the day-to-day operation of the GBG PD study trial, such as maintaining fidelity; developing procedures for randomization; engaging with parents and the school community; and maintaining the morale of standard classroom (control) teachers.

As a result of the transitions taking place in HISD-the first stage of the district's reorganization was announced in December 2009_-neither the Core Team nor the Schools
Committee was formally established. District oversight did occur; in February 2010, with the support of the new Chief Academic Officer, the HISD study liaison and AIR met with representatives of several HISD departments, including Student Support Services, Multilingual Education, Research and Evaluation, and Professional Development. Staff from these offices have since provided advice on specific topics.

The absence of a Core Team and a Schools Committee delayed the process of school selection and engagement for the GBG PD study. The study team had expected executive principals, the direct line of authority and support to school teams, to play a lead role in the selection of schools and in engaging with the school communities, given their in-depth knowledge of the schools' needs and functioning and their long-standing relationships with the principals, school teams, and school communities. As part of the district's reorganization announced in December 2009, the positions of regional assistant superintendent and executive principal were being abolished. People were at risk of losing their positions, perhaps their jobs, and therefore did not have a vested interest in an initiative in which they would likely have no role. A critical line of trust, authority, and communication between the central office and the schools was thus severed. Instead of schools being selected and principals coming together on the Schools Committee in February 2010 and school engagement taking place from February to May 2010, the first meeting with principals of the selected schools was in May 2010, 3 weeks before the end of the school year. At the suggestion of the principals, the kick-off meeting with teachers was August 9, 2010, the first day teachers reported back to work.

Regarding ad hoc oversight at the community level, in fall 2010, AIR, HFT, HISD, and local preceptors conducted a stakeholder analysis to choose members for a GBG Advisory Council, which first convened in spring 2011. The role of the Advisory Committee is to establish a vision and priorities; examine, critique, determine approval for, and support GBG, given approval; communicate constituents' concerns, values, and priorities to the council; communicate GBG program needs to constituent leaders; continually assess absent constituencies; and work toward institutionalizing GBG. Members represent the school district; parent advocates; higher education; the business community; mental health, welfare, and juvenile justice systems; and community advocates. At the time of this writing, the council has met twice.

\section{Step 6-Work Through Issues of Trust}

Despite the shifting and uncertain landscape of HISD over the past 2 years and the absence of HISD ad hoc committees, the collaboration has had much success. The GBG 
PD study is under way; in the 2010-2011 school year, more than 1,500 first graders were randomly assigned to classrooms; four local GBG coaches were trained; and 40 firstgrade teachers implemented GBG. In addition, two more grants have been funded. The first, a research grant funded by NIDA and based at AIR, builds on the GBG PD study and focuses on studying the factors that enhance or impede sustainability and program adaptation; the second, a services grant funded by the Substance Abuse and Mental Health Services Administration (SAMHSA) and based at HISD, focuses on developing district capacity to implement and sustain GBG. By 2015, over 100 HISD first- and second-grade teachers will be trained and over 7,000 students will have been exposed to GBG.

The successes of the GBG PD study and the broader research and practice agenda over the past 2 years can be attributed, in large part, to the established relationships among individuals in HISD, HFT, and the broader community and the relationships developing between these individuals and AIR. Throughout the life of the partnership, HFT has drawn on personal relationships with district and community leaders to develop support for GBG and the GBG PD study. In the absence of an established Core Team, the district's study liaison and her staff led the process of school selection. They and HFT engaged with principals to explain the GBG PD study and elicit support.

The relationships at the school level were fragile during the first year of implementation. Schools Committee meetings would have provided structure and time for principals to discuss concerns, propose procedures, and develop a sense of trust and ownership for the study. For example, the design of the GBG PD study relies on random assignment of students and teachers. The Schools Committee would have developed the procedures for assigning students and teachers as well as the approach for engaging with the school communities. While AIR research staff traveled to Houston and visited each school several times between May and September 2010 to answer questions and discuss study procedures, there was little time to develop relationships. In large part, principals, teachers, and parents initially joined the study on the basis of trust existing in already-established relationships-principals with the study liaison and HFT; teachers and school staff with their principals; and parents with teachers and principals. Trust with AIR has developed over the first year of implementation as a result of working together.

\section{Lessons Learned}

The approach to collaboration used in the Baltimore trials has proved to be a successful framework for developing a partnership in another locale.
Trust as the Foundation of Partnerships

In this partnership, trust between individuals has enabled the work to move forward during times of uncertainly, stress, and external pressures. Relational trust was essential-among HFT, senior leaders in the school district, and school board members as the collaboration began; between the study liaison and principals and between HFT and principals as schools were selected for the GBG PD study and GBG moved into schools as a service; and among the authors who serve as the leads for HISD, HFT, and AIR. Developing relationships based on trust is a process, not an event. It takes time and requires interaction. AIR staff have visited Houston, on average, at least once a month from July 2011 to the present time. The authors have made time for personal interactions both during and outside of office hours, such as sharing meals, attending events, and presenting together at conferences. AIR staff have also cultivated relationships with the local GBG coaches and with school staff.

\section{Develop Structures to Support Collaboration}

At the district level, the absence of a well-defined Core Team and a Schools Committee created challenges above and beyond slowing the process of base-building with school communities. Roles and responsibilities among the three institutions have not always been clear, particularly with regard to decision-making. The roles and responsibilities of AIR and HISD are clearly delineated for the GBG PD study. Over the past 2 years, AIR and HISD have made decisions on a wide range of issues, such as choosing a third-party provider of professional development, with whom AIR contracted to deliver GBG coaching, and developing study protocols for school selection, garnering informed consent, and randomly assigning students to classrooms and teachers to intervention conditions. They also worked closely on the grant submission to SAMHSA.

The AIR and HISD study leads have maintained regular, frequent contact by phone and email and in person. Given the successes cited above, this communication style appears to have been effective. However, contact with HFT has been markedly less regular and less frequent, and the absence of HFT has mattered. For example, in the first year of implementation, it was challenging to engage parents and to garner parental consent for students to participate in data collection activities for the study. Teachers and other school staff who are critical to the process of parent engagement were themselves just learning about GBG and the study. HFT has staff members who could have supported school principals and teachers as they engaged parents and garnered. However, HFT was not involved in the conversations of progress review and so could not offer 
assistance. Ad hoc committees provide a structure for members to share challenges and explore solutions, and to develop procedures for collaborative decision making. In retrospect, a regularly scheduled meeting among the study leads from each institution would have been useful. The lack of a Core Team with membership from HISD, AIR, and HFT created inefficiencies in the work, particularly for the HISD study liaison. During the process of decision making, she often had to engage and follow up with individuals who would have been together on a Core Team. Overall, the practice of continually referring back to the roles of the proposed district ad hoc committees helped focus activities, but it has not been an adequate substitute for more formal structures.

At the community level, events described in this paper demonstrate that establishing a broad community institution base can provide stability of mission and focus for collaborations, particularly in times of leadership transition. The GBG Advisory Council is in its inception and beginning to define its mission and structure. Given the challenging economic times and the fiscal constraints within districts, a key focus of the council will be to use its influence to identify and ensure funding for GBG sustainability and expansion within HISD and other districts.

The experience of the field has shown that sustainable systems change requires changes to policy, staffing patterns, and resource allocations, as well as to the beliefs and values of an organization (Schlechty 1997). Realizing the vision of bringing GBG to HISD and the broader Houston community with sustainability over time and forwarding the research agenda through activities such as the longitudinal follow-up of the students and teachers participating in the GBG PD study will require governance structures within HISD as well as the broader support afforded by an Advisory Council.

\section{Implications for the Next Stage of Research and Practice}

For programs and strategies to be used, they must be relevant to the mission and vision of community institutions-in our case, districts and schools-and to the work of those who use them- the teachers. They must be feasible for staff to use and maintain over time and be replicable across schools and districts. Community and institution boards such as the GBG Advisory Council have the power to ensure the local sustainability and expansion of programs through leveraging their influence on elected officials, being able to raise funds, and sharing information with their constituencies.

Collaboration among institutions, community advocates, researchers, policymakers, and funders locally as well as at the state and federal levels will become increasingly important as the fields of prevention and education expand to take on questions of sustainability and dissemination. Type 2 Translational or implementation research aims at moving efficacious programs and strategies into practice and addresses questions regarding implementation, sustainability, and adaptation (Fixsen et al. 2005; NIDA 2009; SPR 2009). There is a longstanding and well-developing tradition of evaluation research in the field of education. Classes of research designs employing random assignment used in clinical medicine and public health can guide implementation research in the field of education.

One example is the dynamic wait-list design (Brown et al. 2006) in which subjects (e.g. teachers, or schools) are randomly assigned as to when they receive training and implement the intervention. This design aligns well with the usual practice of districts when programs are rolled out gradually as the intervention reaches everyone within a specified time period. Another example is employing a variation of run-in designs, a concept often used in clinical trials. Consider a district in which professional development is to be rolled out to principals. The year before any training commences, data are collected from all the principals in the district on a range of variables. A randomized field trial can then be designed and conducted in schools where principals are well matched with regard to variables of interest. Stratification can be employed to match principals at various levels of the same variables. Both of these designs require planning the research and the program adoption in parallel-before training and program implementation begin. Partnerships among districts, researchers, and communities provide opportunity to consider districts' needs, plan research designs that are in keeping with the mores of the districts and communities, and develop timelines that support obtaining funding for a broad practice and research agenda. Policymakers and funding agencies across all levels-local, state, and federal-influence the extent to which these agendas can be developed through the requirements of programs announcements and requests for proposals.

Training programs in fields such as public health and community psychology have long offered students opportunities for conducting research in partnership with communities and their institutions. Providing the next generation of researchers and practitioners the skills to develop and lead transdisciplinary, cross-agency teams, with multiple-level membership and representation of the community's advocates, will support bringing together the knowledge and advances being made in areas such as brain development, genetics, and systems sciences with educational practice. 
Acknowledgments There would be no collaboration without the support and efforts of many members of the Houston Independent School District community, including the principals, teachers, children and parents, data clerks, and numerous other staff members in schools implementing the Good Behavior Game; central office staff; and the School Board. In addition, members of the broader Houston community have generously shared their experiences and good thinking with us. We thank you all. We also thank AIR staff members who have participated in making this collaboration a success. We acknowledge Dr. Sheppard Kellam, who provided a framework for our approach to collaboration. The following grants have provided funding for this work: National Institute on Drug Abuse R21DA024370 and Institute of Education Sciences R305A090446. Neither institute had a role in the writing of the paper or the decision to submit the paper for publication.

Open Access This article is distributed under the terms of the Creative Commons Attribution Noncommercial License which permits any noncommercial use, distribution, and reproduction in any medium, provided the original author(s) and source are credited.

\section{References}

Barrish, H. H., Saunders, M., \& Wolf, M. M. (1969). Good behavior game: Effects of individual contingencies for group consequences on disruptive behavior in a classroom. Journal of Applied Behavior Analysis, 2(2), 119-124.

Bradshaw, C. P., Zmuda, J. H., Kellam, S. G., \& Ialongo, N. S. (2009). Longitudinal impact of two universal preventive interventions in first grade on educational outcomes in high school. Journal of Educational Psychology, 101(4), 926-937.

Brown, C. H. (1993). Analyzing preventive trials with generalized additive models [Special issue on Methodological Issues in Prevention Research]. American Journal of Community Psychology, 21, 635-664.

Brown, C. H., Wyman, P. A., Guo, J., \& Peña, J. (2006). Dynamic wait-listed designs for randomized trials: New designs for prevention of youth suicide. Clinical Trials, 3, 259-271.

Council of the Great City Schools. (2009). Urban school superintendents: Characteristics, tenure, and salary: Sixth survey and report. Washington, DC: Author.

Dishion, T. J., Spracklen, K. M., Andrews, D. W., \& Patterson, G. R. (1996). Deviancy training in male adolescent friendships. Behavior Therapy, 27(3), 373-390.

Dolan, L. J., Kellam, S. G., Brown, C. H., Werthamer-Larsson, L., Rebok, G. W., Mayer, L. S., et al. (1993). The short-term impact of two classroom-based preventive interventions on aggressive and shy behaviors and poor achievement. Journal of Applied Developmental Psychology, 14(317), 345.

Eng, E., Moore, K. S., Rhodes, S. D., Griffith, D. M., Allison, L. L., Shriah, K., et al. (2005). Insiders and outsiders assess who is "the community". In B. A. Israel, E. Eng, A. J. Schulz, \& E. A. Parker (Eds.), Methods in community-based participatory research for health (pp. 77-100). San Francisco: Jossey-Bass.

Ensminger, M. E., \& Slusarcick, A. L. (1992). Paths to high school graduation or dropout: A longitudinal study of a first-grade cohort. Sociology of Education, 65(2), 95-113.

Evertson, C. M., \& Weinstein, C. S. (2006). Handbook of classroom management: Research, practice, and contemporary issues. Mahwah, NJ: Erlbaum.

Fixsen, D. L., Naoom, S. F., Blasé, K. A., Friedman, R. M., \& Wallace, F. (2005). Implementation research: A synthesis of the literature (FMHI Publication \#231). Tampa: University of South
Florida, Louis de la Parte Florida Mental Health Institute, The National Implementation Research Network.

Furr-Holden, C. M., Ialongo, N. S., Anthony, J. C., Petras, H., \& Kellam, S. G. (2004). Developmentally inspired drug prevention: Middle school outcomes in a school-based randomized prevention trial. Drug and Alcohol Dependence, 73(2), 149-158.

Houston Independent School District (2010). Purpose, strategic intent, goals, and core values. Retrieved December 23, 2010, from http://www.houstonisd.org/

Ialongo, N. S., Poduska, J. M., Werthamer, L., \& Kellam, S. (2001). The distal impact of two first-grade preventive interventions on conduct problems and disorder in early adolescence. Journal of Emotional and Behavioral Disorders, 9, 146-160.

Ialongo, N. S., Werthamer, L., Kellam, S. G., Brown, C. H., Wang, S., \& Lin, Y. (1999). Proximal impact of two first-grade preventive interventions on the early risk behaviors for later substance abuse, depression, and antisocial behavior. American Journal of Community Psychology, 27(5), 599-641.

Kellam, S. G. (2000). Community and institutional partnerships for school violence prevention. Plenary papers of the 1999 conference on criminal justice research and evaluation-enhancing policy and practice through research (NCJ 180972), Vol. 2, pp. 1-21.

Kellam, S. G., \& Anthony, J. C. (1998). Targeting early antecedents to prevent tobacco smoking: Findings from an epidemiologically based randomized field trial. American Journal of Public Health, 88(10), 1490-1495.

Kellam, S. G., \& Branch, J. D. (1971). Approach to community mental health: Analysis of basic problems. Semin Psychiatry, $3(1), 207-225$.

Kellam, S. G., Ling, X., Merisca, R., Brown, C. H., \& Ialongo, N. (1998). The effect of the level of aggression in the first grade classroom on the course and malleability of aggressive behavior into middle school. Development and Psychopathology, 10(2), 165-185. See also Kellam, S. G., Ling, X., Merisca, R., Brown, C. H., \& Ialongo, N. (2000). Erratum. Development and Psychopathology, 12, 107.

Kellam, S. G., Poduska, J. M., Ialongo, N. S., Wang, W., Toyinbo, P., Petras, H., et al. (2008). Effects of a universal classroom behavior management program in first and second grades on young adult behavioral, psychiatric, and social outcomes. Drug and Alcohol Dependence, 95, 5-28.

Kellam, S. G., Rebok, G. W., Ialongo, N., \& Mayer, L. S. (1994). The course and malleability of aggressive behavior from early first grade into middle school: Results of a developmental epidemiologically-based preventive trial. Journal of Child Psychology and Psychiatry, 35(2), 259-281.

National Council for Accreditation of Teacher Education. (2002). Professional standards for the accreditation of schools, colleges, and departments of education. Washington, DC: Author.

National Institute on Drug Abuse. (2009). Five-year strategic plan. Bethesda, MD: Author.

Orr, M. (2007). Transforming the city: Community organizing and the challenge of political change. Lawrence: University Press of Kansas.

Patterson, G. R., Reid, J. B., \& Dishion, T. J. (1992). Antisocial boys. Eugene, OR: Castalia.

Petras, H., Kellam, S. G., Brown, C. H., Muthen, B. O., Ialongo, N. S., \& Poduska, J. M. (2008). Developmental epidemiological courses leading to antisocial personality disorder and violent and criminal behavior: Effects by young adulthood of a universal preventive intervention in first- and second-grade classrooms. Drug and Alcohol Dependence, 95(Suppl 1), S45-S59.

Poduska, J., Kellam, S., Brown, C. H., Ford, C., Windham, A., Keegan, N., et al. (2009). Study protocol for a group randomized controlled trial of a classroom-based intervention aimed at 
preventing early risk factors for drug abuse: Integrating effectiveness and implementation research. Implementation Science, $4,56-57$.

Poduska, J. M., Kellam, S. G., Wang, W., Brown, C. H., Ialongo, N. S., \& Toyinbo, P. (2008). Impact of the good behavior game, a universal classroom-based behavior intervention, on young adult service use for problems with emotions, behavior, or drugs or alcohol. Drug and Alcohol Dependence, 95(Suppl 1), S29-S44.

Schlechty, P. C. (1997). Inventing better schools: An action plan for educational reform. San Francisco: Jossey-Bass.

Shirley, D. (1997). Community organizing for urban school reform. Austin: University of Texas Press.

Society for Prevention Research. (2009). Position statement of the Society for Prevention Research MAPS Type 2 Translational Research Task Force on type 2 translational research. Fairfax, VA: Author.
Stone, C. N. (2001). Building civic capacity: The politics of reforming urban schools. Lawrence: University Press of Kansas.

Storr, C. L., Ialongo, N. S., Kellam, S. G., \& Anthony, J. C. (2002). A randomized controlled trial of two primary school intervention strategies to prevent early onset tobacco smoking. Drug and Alcohol Dependence, 66(1), 51-60.

Walter, H. J., Gouze, K., \& Lim, K. G. (2006). Teachers' beliefs about mental health needs in inner city elementary schools. Journal of the American Academy of Child and Adolescent Psychiatry, 45(1), 61.

Wilcox, H. C., Kellam, S. G., Brown, C. H., Poduska, J. M., Ialongo, N. S., Wang, W., et al. (2008). The impact of two universal randomized first- and second-grade classroom interventions on young adult suicide ideation and attempts. Drug and Alcohol Dependence, 95(Suppl 1), S60-S73. 